\title{
CONTINOUS LIGHT DAN ARTIFICIAL LIGHT PADA KARYA PORTRAIT FOTOGRAFI BANTENGAN
}

\author{
Andhika Putra Herwanto ${ }^{1}$, Andika Agung Sutrisno ${ }^{2}$ \\ ${ }^{\mathbf{1 , 2}}$ Program Studi Desain Komunikasi Visual, Jurusan Seni dan Desain Universitas Negeri Malang \\ andhika.putra.fs@um.ac.id ${ }^{\mathbf{1}}$, andika.agung.fs@um.ac.id ${ }^{2}$
}

\begin{abstract}
Photography is present as a unique distinction, namely the ability to speak and writing and make it partially, out of date. Knowledge of the subject and its implications is important for photographers in addition to the technical issues of lens optimization. When making portraits, photographers carry out activities to interpret object (model) photos. In photography, lighting or lighting can be classified into various discussion topics. Generally these discussions are related to light sources. When viewed from the source, the available light can be divided into two, namely continous light and artificial light
\end{abstract}

\section{Key Words: Portrait Photography, Continous Light, Artificial Light}

\begin{abstract}
Abstrak: Fotografi hadir sebagai unique distinction, yaitu kemampuannya berbicara (spoken) dan tulisan (writen) dan membuat menjadi partially (not complete), out of date (tidak bertahan lama). Pengetahuan subject dan implikasinya menjadi penting bagi fotografer selain persoalan teknikal optimalisasi lensa. Ketika membuat portrait, fotografer melakukan kegiatan menafsirkan objek (model) foto. Penelitian ini akan menggunakan metode deskriptif kualitatif yang dilakukan mulai tahap pengumpulan data, tahap analisis dan tahap interpretasi.Dalam fotografi, pencahayaan atau lighting dapat digolongkan ke dalam berbagai topik bahasan. Umumnya pembahasan tersebut berkaitan dengan sumber cahaya. Bila ditinjau dari sumbernya, cahaya yang ada bisa dibagi menjadi dua, yaitu cahaya alam (continous light) dan cahaya buatan (articial light)
\end{abstract}

Kata kunci: fotografi portrait, continuous light, artificial light

Fotografi portrait merupakan representasi kemiripan figur manusia dalam bentuk dwimatra. Dominasi manusia sebagai subjek foto membedakan jenis fotografi potrait dengan yang lain. Penciptaan seni potrait dalam bentuk seni lukis, patung, dan grafis sudah ada sejak belum ditemukannya fotografi. Selain representasi, fotografi juga digunakan sebagai komunikasi atau medium rekam (Dennet, 2001: 16-17) dan dianggap sebagai ekspresi diri fotografer. Foto merefleksikan kepedulian fotografer. Disisi lain, fotografi dianggap juga sebagai sebuah seni (O'Brien, 1995: 7) yang merupakan ekspresi sebuah visi personal fotografer.

Fotografi hadir sebagai unique distinction, yaitu kemampuannya berbicara (spoken) dan tulisan (writen) dan membuat menjadi partially (not complete), out of date (tidak bertahan lama). Pengetahuan subject dan implikasinya menjadi penting bagi fotografer selain persoalan teknikal optimalisasi lensa. Ketika membuat portrait, fotografer melakukan kegiatan menafsirkan objek (model) foto. Fotografer mengatakan sesuatu dengan bahasa foto. Foto memberikan isyarat pendek melalui objek foto. Objek foto yang paling banyak digunakan adalah manusia dan merupakan bagian dari portraiture photography (potrait fotografi). Potraiture merupakan usaha fotografer untuk menjawab pertanyaan subjek tentang "what do I look like?", "what am I like", "who am I". Potrait (Douglas, 2011: 30) dapat menentukan karakter dan kepribadian serta mengatakan di mana objek (model) foto; bekerja atau bermain.

Dalam fotografi, pencahayaan atau lighting dapat digolongkan ke dalam berbagai topik bahasan. Umumnya pembahasan tersebut berkaitan dengan: (1) sumber cahaya. Bila ditinjau dari sumbernya, cahaya yang ada 
bisa dibagi menjadi dua, yaitu cahaya alam (natural light) dan cahaya buatan (articial light), yaitu cahaya yang sengaja ditambahkan untuk keperluan pemotretan, seperti penggunaan flash, strobist, studio flash/ monoblok, dan aksesoris pendukung lainnya. Walau sifatnya buatan, articial light menyerupai natural light; (2) fungsi pencahayaan: (a) main light, (b) in light, dan (c) effect light; (3) sifat cahaya. Berdasarkan sifatnya, cahaya dapat dibagi menjadi: (a) hard light, (b) semi soft light, (c) soft light; (4) pola pencahayaan: (a) broad light (cahaya menyebar), (b) narrow ligth (cahaya terarah/menyempit), (c) spot light (cahaya spot).

Menurut Adimodel (2009:24-25) mengetahui rasio pencahayaan sangatlah penting. Sebagai contoh: antara main light dan effect light, maka rasio intensitas effect light harus lebih besar. Jika rasio main light lebih besar, kesan yang ditimbulkan pada effect light tidak akan terlihat hasilnya, begitu juga seterusnya.

Continous light adalah jenis pencahayaan alam yang mana cahaya tersebut dihasilkan dari seluruh unsur alam. Unsur utama dalam pencahayaan alami bersumber pada cahaya matahari. Adapun pencahayaan matahari memiliki jam-jam tertentu yang baik untuk digunakan sebagai sumber cahaya dalam pemotretan. Untuk pagi hari antara $08.00-$ 10.00 dan untuk sore hari 15.00 - matahari terbenam. Hal ini dikarenakan pada jam-jam tersebut kekuatan sinar matahari tidak terlalu kuat, dan sudut pencahayaannya pun merata. Karakteristik perubahan cahaya alami tergantung pada hari, cuaca, musim atau karena keadaan lainnya. Pada dasarnya ada jenis cahaya yang berbeda pada setiap waktu. Jenis-jenis cahaya yang berbeda akan membuat sebuah adegan (scene) yang sama terlihat sangat berbeda.

Dalam fotografi ada istilah high key and low key. Secara sederhana maksud high key adalah fotografi yang nuansa cahayanya terang, sedangkan low key adalah fotografi yang nuansa cahayanya gelap. Biasanya teknik high-key dan low key ini banyak disebut-sebut untuk pemotretan portrait manusia, terutama dalam setting studio/indoor, dimana fotografer mengendalikan penuh sifat cahaya, arah, penyebaran, dan intensitas cahaya.
Banyak cara membuat foto terlihat lebih berdimensi, salah satunya adalah dengan memperhatikan pencahayaan. Selain penggunaan cahaya yang ada (available light), umumnya fotografer menggunakan tambahan artifisial light berupa lampu studio atau speed light yang dikenal juga dengan istilah Flash. Penggunaan flash ini biasanya lebih mudah dan efisien, orang menyebut dengan nama teknik Strobist dan dalam satu pemotretan jumlah flash yang digunakan bisa beragam jumlahnya, bisa satu, dua, tiga hingga lebih untuk membuat foto sesuai dengan yang diinginkan

\section{FOTOGRAFI PORTRAIT BANTENGAN}

Data visual berupa karya portrait fotografi pemain bantengan sebagai berikut:
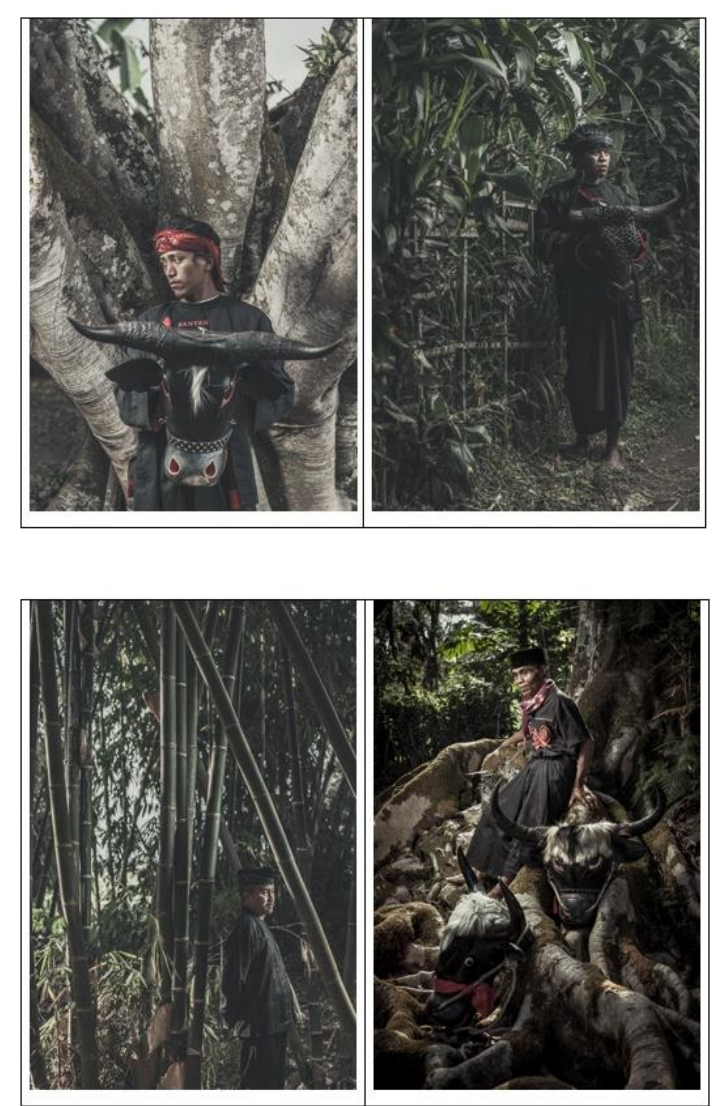

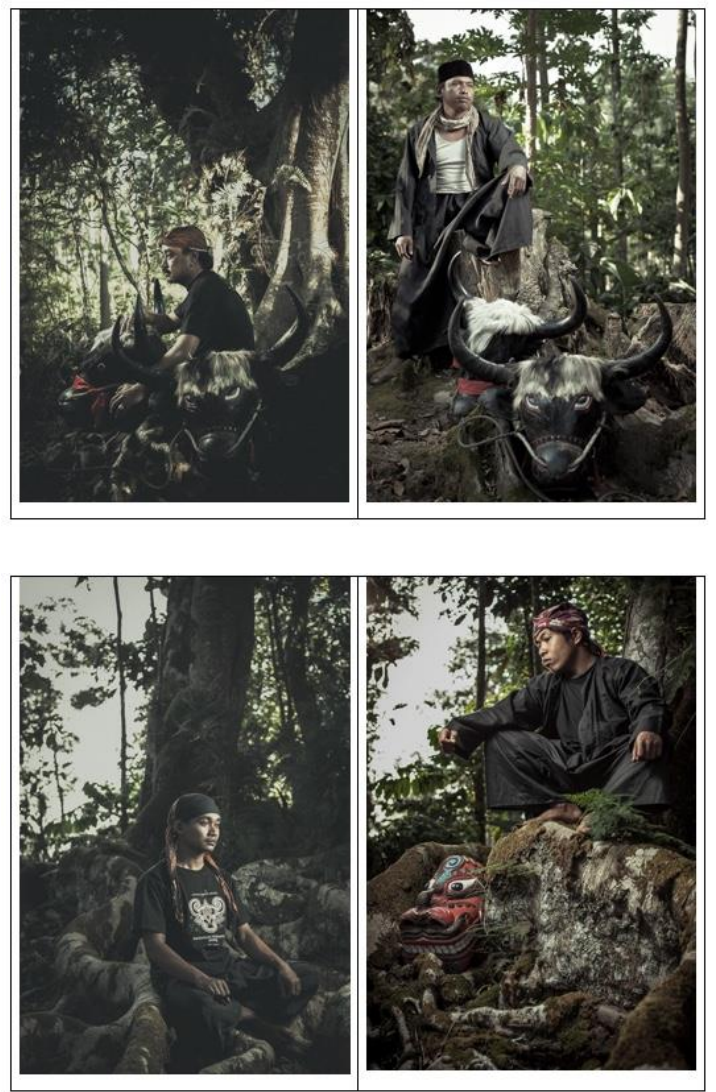

Gambar 1 fotografi portrait

Sumber: Febrianto Wihanda Putra

\section{METODE}

Penelitian ini akan menggunakan metode deskriptif kualitatif yang dilakukan mulai tahap pengumpulan data, tahap analisis dan tahap interpretasi. Data berupa karya fotografi portrait akan dikumpulkan dengan format gambar, dilanjutkan dengan karya fotografi portrait tersebut akan diperlihatkan kepada audiens, dan audiens akan diwawancara untuk menghasilkan feedback, serta hasilnya akan diinterpretasikan untuk mengetahui continuous light dan artificial light pada karya fotografi portret.

\section{PEMBAHASAN}

Pada dasarnya tujuan dan hakekat fotografi adalah komunikasi. Komunikasi yang dimaksud adalah komunikasi antara fotografer dengan penikmatnya, yaitu fotografer sebagai pengantar atau perekam peristiwa untuk disajikan kehadapan khalayak ramai melalui media foto.

Fotografi bisa dikatakan sebagai kegiatan penyampaian pesan secara visual dari pengalaman yang dimiliki seniman/fotografer kepada orang lain dengan tujuan orang lain mengikuti jalan pikirannya. Supaya tercapai proses penyampaian pesan ini maka harus melalui beberapa persyaratan komunikasi yang baik, yaitu konsep AIDA (Attention-InterestDesire-Action) atau Perhatian- Ketertarikan Keinginan - Tindakan (Susanto, 1984: 11).

Syarat pertama adalah harus menimbulkan perhatian (attention). Sebuah karya foto pertama-tama harus mampu mendapatkan perhatian orang untuk melihatnya. Tanpa proses ini, sebuah pesan dari karya foto juga karya seni lainnya akan berhenti di situ saja. Kemudian setelah mampu mendapat perhatian orang maka karya foto harus mampu menimbulkan ketertarikan (interest) terhadap pesan yang akan disampaikan. Setelah orang tertarik pada karya foto yang dibuat, maka dari situ proses tetap berlangsung dengan timbulnya keinginan (desire) untuk mengetahui lebih jauh pesan yang disampaikan. Proses terakhir adalah dengan timbulnya tindakan (action) seperti yang diharapkan oleh seniman/fotografer sesuai pesan yang disampaikannya. Jika proses terakhir ini berhasil, maka berhasil pulalah penyampaian pesan mengenai pengalaman yang dimiliki seniman/fotografer pada orang lain dengan adanya tindakan nyata yang dilakukan. Tindakan-tindakan itu bisa beraneka macam tergantung pesan apa yang akan disampaikan, bisa menimbulkan perasaan tertentu (sedih, gembira, marah, takut, terharu, dan lain-lain) hingga tindakan nyata.

Fotografi portrait merupakan representasi kemiripan figur manusia dalam bentuk dwimatra. Dominasi manusia sebagai subjek foto membedakan jenis fotografi potrait dengan yang lain. Penciptaan seni potrait dalam bentuk seni lukis, patung, dan grafis sudah ada sejak belum ditemukannya fotografi.

Kajian foto wajah dalam portrait menurut Yuyung abdi (2012:165) tidak serupa dengan foto untuk identitas, seperti halnya foto KTP. Foto portrat wajah lebih menekankan 
kedalaman makna subjek. Foto ini lebih menekankan bagaimana mengankat karakter seseorang. Karena karakter seseorang berhubungan erat dengan latar belakang kehidupan dia. Lingkungan yang ada di sekitarnya bisa juga memperkuat tampilan, sekaligus memperkuat maknanya. Hanya saja ketika memotret wajah model dengan profil, seseorang punya konteks yang berbeda dalam deskirpsinya. Model menampilkan keadaan yang paling bagus dalam sisi fisik. Sementara foto profil tidak harus tampil dalam keadaan menarik atau cakap. Tapi, aksentuasinya sosok juga ditujukan untuk menampilkan cerita dibalik dirinya. Perbedaaan menangkap moment pada foto profil, bisa pose, dangan mengarahkan ke kamera, meskipun tidak melihat kamera pada saat beraksi maupun berekspresi.

Seperti yang kita ketahui bersama bahwa fotografi itu adalah sebuah tehnik melukis dengan cahaya, atau dengan kata lain kita bermain-main dengan cahaya, memiliki cahaya yang semakin bagus maka potensi memiliki foto bagus akan semakin besar kemungkinannya. Oleh karena itu cahaya adalah sebuah komponen yang paling penting bagi seorang fotografer.

Cahaya disekitar kita dihasilkan oleh berbagai jenis sumber cahaya. Pada siang hari ada sumber cahaya alami berupa mataharim, sedangkan pada malam hari kita bisa dengan mudah menemukan sumber cahaya buatan berupa lampu penerangan jalan yang umumnya adalah lampu Sodium Vapor. Di dalam ruangan juga bisa menemukan lampu bohlam incandescent, lampu fluorescent, dan LED. Masing-masing sumber cahaya memiliki cara kerja dan efek yang berbeda.

Fotografer akan

selalu mempertimbangkan arah cahaya, baik itu cahaya alami atau cahaya buatan. Kualitas cahaya ini sendiri sangat beragam, baik itu cahaya matahari atau cahaya dari lampu-lampu atau benda yang berpijar dan menghasilkan cahaya. Kualitas cahaya matahari tergantung pada jam dan posisi matahari, misalnya cahaya matahari pagi beda dengan cahaya matahari sore.

Continous light adalah pencahayaan yang sudah ada di suatu lingkungan tanpa campur tangan fotografer. Contoh yang paling lazim adalah matahari dan lampu penerangan jalan. Pada umumnya jenis cahaya ambient merupakan continous light, dengan pengecualian hanya untuk petir. Pada prakteknya, kita tidak bisa mengatur setelan continous light secara langsung. Sebagai contoh matahari, kita tidak bisa menggeser sudutnya dan tidak ada tombol untuk mengatur intensitasnya. Cara mengendalikan pengaruh ambient adalah dengan pengaturan tidak langsungc seperti pemilihan lokasi dan waktu.

Artificial light adalah pencahayaan yang dipersiapkan khusus untuk pemotretan. Seperti flash built-in pada kamera. Bentuk dari artificial light bisa berupa continous light, atau bisa juga strobe seperti lampu flash. Setelan artificial light bisa diatur sesuai kebutuhan, diantaranya adalah posisi, sudut, dan intensitas pencahayaan. Lampu flash modern bahkan memiliki fitur cerdas untuk mengatur power secara otomatis dengan membaca jumlah cahaya yang melalui lensa kamera, yang sering disebut sebagai TTL (Through The LENS). (Dharsito,2014)

Tabel 1. Identifikasi artificial light

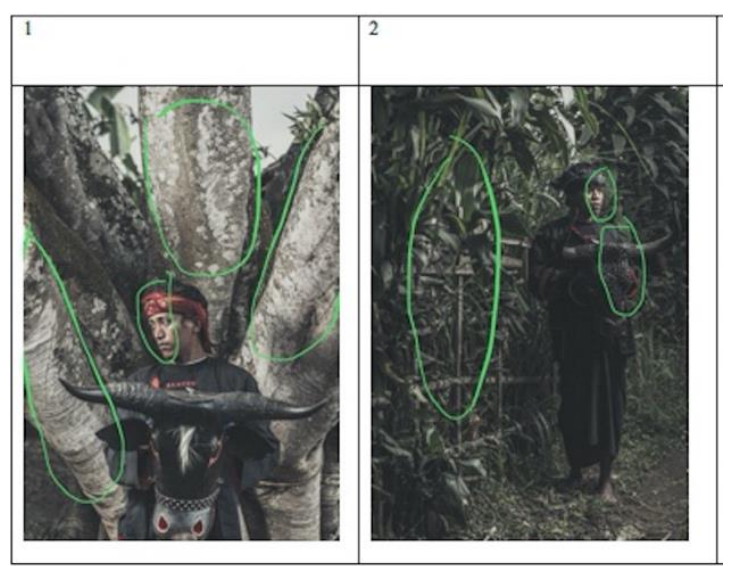



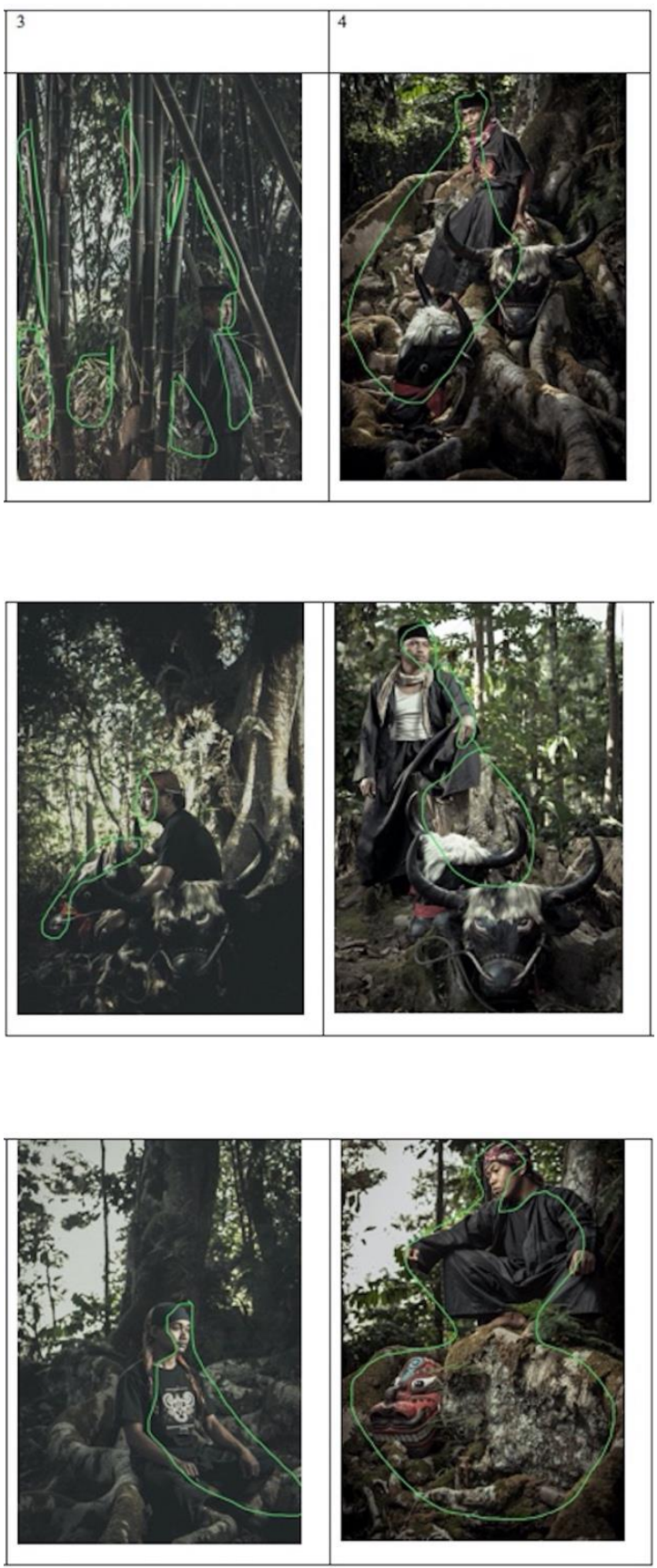

Pada tabel 1 telah diidentifikasi artificial light yang ada pada karya portrait pemain bantengan. Pada artificial light pada keseluruhan karya langsung diarahkan kepada model portrait, tepatnya mengarah untuk menerangi wajah dari model. Cahaya artificial pada karya ini memakai jenis aksesoris yang digunakanan untuk pemotretan ini mempunyai karakter cahaya soft, dimana dapat dilihat dari contras antara shadow dan hightlight. Namun, intensitas cahaya yang digunakan sangat besar karena mengingat kondisi pemotretan yang dilakukan di luar ruangan dan juga terdapat cahaya matahari. Selain itu aksesoris yang digunakan untuk artificial light juga harus mempunyai dimensi yang besar, dapat dilihat dari sebaran cahaya yang ada pada objek foto.

Hasil dari penggunaan artificial light pada akhirnya akan memberikan dimensi pada karya foto sesuai dengan prinsip-prinsip rupa dimana dimensi sangat dibutuhkan untuk menambah kesan pada karya foto portrait tersebut, selain itu dengan kondisi pemotretan luar ruang yang kondisi pencahayaan banyak tertutup oleh pepohonan maka penggunaan artificial light sangat membantu dalam menghasilkan foto portrait.

Secara umum prinsip desain tersebut dapat menciptakan sebuah estetika atau keindahan dalam sebuah desain. Keindahan ini penting karena merupakan daya tarik bagi audience agar melihat secara lebih detail dan seksama. Hal ini sesuai dengan pendapat mayoritas responden bahwa estetika selain sebagai daya tarik awal karya fotografi juga merupakan pendukung agar informasi dapat disampaikan secara efektif.

Tabel 2. Identifikasi continous light

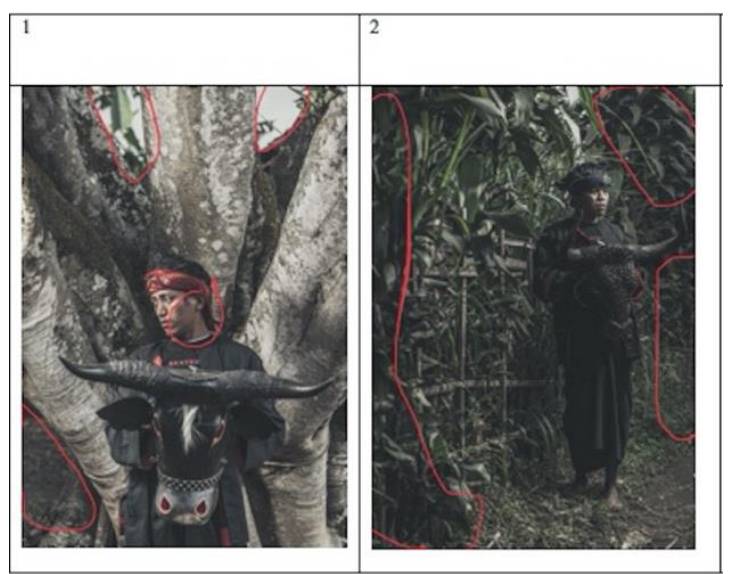



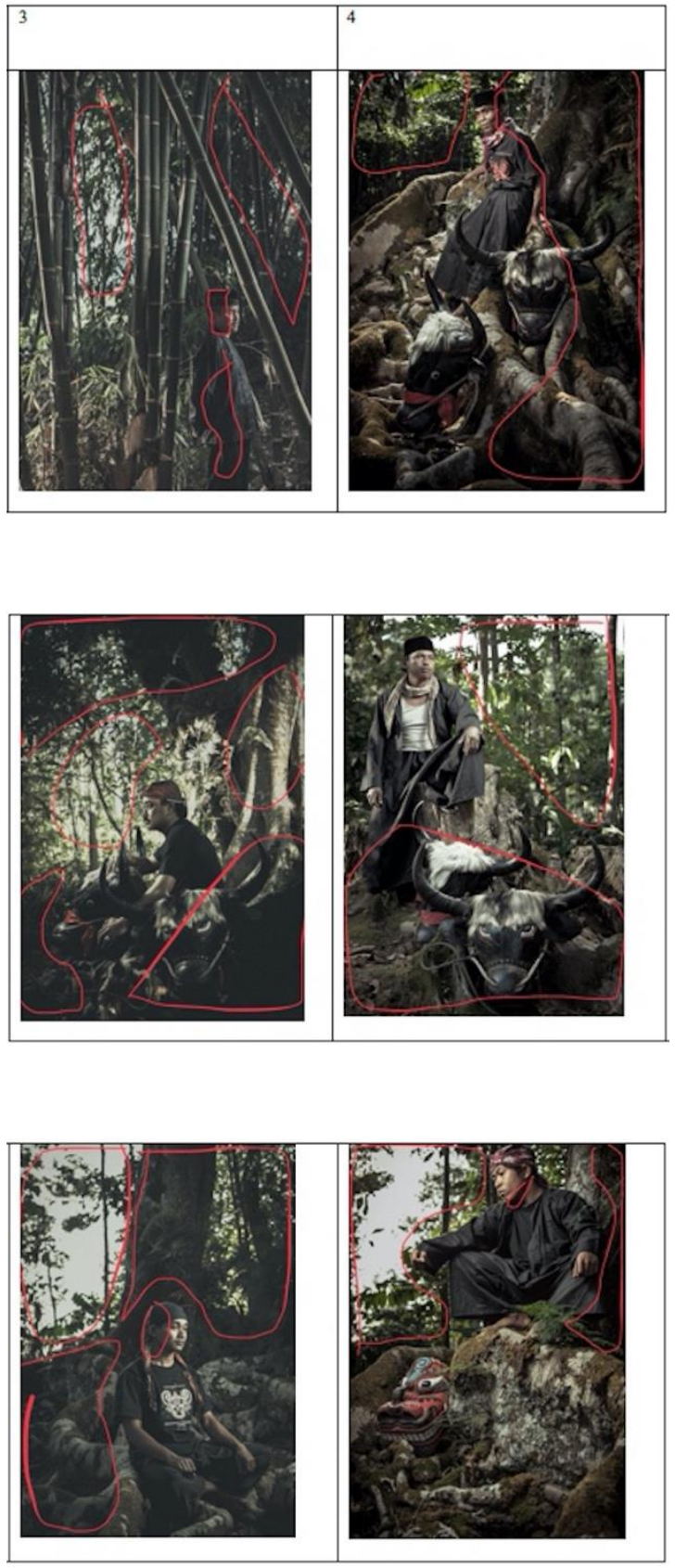

Pada tabel 2 mengidentifikasi continuous light yang ada pada karya portrait pemain bantengan. Pada karya-karya tersebut continuous light tetap mempertahankan ambience light, agar tetap mengesankan keadaan yang terjadi ketika pengambilan gambar dilakukan. Continuous light disini juga masih ada pada object foto, dalam hal ini para pemain bantengan atau model. Shadow yang ada pada pemain bantengan, tepatnya dapat dilihat pada bagian wajah sang pemain, merupakan continuous light. Dan juga shadow yang merata pada full body ketika long shot juga merupakan continuous light.

Secara keseluruhan pada karya portrait fotografi ini artificial light sangat dibutuhkan untuk lebih menunjukkan karakter tokoh atau model pemain bantengan, dan juga agar hasil dari foto juga lebih berdimensi, mengingat highlight pada wajah yang merupakan Point of interest pada foto merupakan hasil dari artificial light, sedangkan shadow yang ada merupakan continuous light. Tidak dapat diungkiri, saat dilihat dari foto portrait tersebut, jika fotografer hanya menggunakan satu sumber cahaya yakni continuous light maka akan tidak ada dimensi pada posisi model, sehingga menambahkan satu sumber cahaya dari artificial light sangat membantu dalam kondisi pemotretan diatas. Selain itu perhitungan nilai stop juga sangat penting, dapat dilihat secara keseluruhan antara artificial light yang ada pada tokoh bantengan dan juga continuous light baik langit ataupun ambience yang ada di sekitar model tidak terlalu tinggi, antara satu sampai satu setengah stop.

Penggunaan flash adalah salah satu cara membuat foto menjadi lebih berdimensi, bukan hanya sekedar untuk menerangi objek saja. Jika kita melihat foto kita menjadi dua bagian, yaitu bagian foreground dan background, maka untuk membuat foto menjadi lebih berdimensi, kita harus bisa memberikan ruang tersendiri antara foreground dan background dan kita bisa melakukan itu dengan tambahan cahaya dari flash atau juga dengan DOF.

Dari karya portrait ini juga dapat dilihat bagaimana artificial sangat membantu menghasilkan dimensi dalam sebuah foto portrait ketika digabungkan dengan aksesoris dan juga ditambah dengan pengaturan nilai stop pada continuous light yang ada pada saaat melakukan pemotretan. Hasil penelitian terhadap responden juga mengatakan demikian, mayoritas menyebutkan bahwa artificial light sangat membantu menghasilkan karya yang berdimensi ketika dikombinasikan dengan continuous light. 


\section{REFERENSI}

Abdi, Yuyung. (2012). Photography From My Eyes. Jakarta, Elex Media Komputindo.

Adimodel. (2009). Lighting with one light, Jakarta: PT Elex Media Komputindo Kompas Gramedia Building

Dharsito, Wahyu. (2014). Basic Lighting for Photography. Jakarta, Elex Media Komputindo.

Dennet, Terry dan Jo Spence. (2001). Photography, Ideology and Education" dalam The Screen Education Reader:
Cinema, Television, Culture, Editor Manuel Alvarado, Edward Buscombe dan Richard Collins. New York:Palgrafe

Douglas, Phil. (2011). Defining Character and Personality with Expressive Portraiture, PSA Journal, Ed. March

O'Brien, Michael E dan Norman Sibley.(1995). The Photographic Eye: Learning to See With a Camera. Worcester: Davis Publications Inc Susanto, Astrid S. (1979), Komunikasi Dalam Teori dan Praktek, Binacipta, Bandung. 